\title{
INFORMALIDADE E CRISE SOCIAL NO BRASIL: UM OLHAR SOBRE O TRABALHO DIGITAL PRECARIZADO
}

\author{
Gleyce Kelly de Miranda ${ }^{1}$ \\ Sónia Maria Fonseca Pereira Oliveira Gomes²
}

RESUMO: O processo de desestruturação do mercado de trabalho brasileiro tem culminado em elevadas taxas de desemprego e precarização das relações trabalhistas, conforme atestam dados recentes do IBGE. O presente artigo tece considerações acerca da informalidade no Brasil, com enfoque no trabalho digital precarizado dos entregadores por aplicativos, visto que se configuram como um dos grupos sociais com maior exposição às condições precarizadas de trabalho. Como apontam os resultados, há indicativos de intensa jornada de trabalho, baixa remuneração, baixa proteção social e falta de autonomia no gerenciamento da força de trabalho. O estudo analisa ainda como o fenômeno da terceirização e do trabalho autônomo dialogam com a precarização deste tipo de trabalho e as possibilidades de novas organizações laborais, dentro da legislação trabalhista brasileira.

Palavras-Chave: Informalidade; Crise social; Precarização do trabalho; Trabalho uberizado.

\section{DIFFERENTIAL INCOME BY EDUCATION LEVEL BETWEEN MEN AND WOMEN IN BRAZIL: AN ANALYSIS OF THE FIRST QUARTERS OF 2012, 2015 AND 2019}

\begin{abstract}
The disruption process of the Brazilian labor market has culminated in high rates of unemployment and present sings of precarious labor relations, based on data from the Brazilian Institute of Geography and Statistics. The purpose of this article is to analyze the informal labor in Brazil, with focus to precarious digital labor of delivery by applications, they are configured as one of the social groups with greater exposure to precarious labor conditions, point out the results. There are indications of intense precarity of their amount of labor and working time, low salary and social protection, the management of the labor force by the algorithm. This article also looks as the phenomenon of outsourcing and self-employment relate to this precarious labor the possibilities for new labor organizations, within Brazilian labor legislation.
\end{abstract}

Keywords: Informality; Social crisis; Precarious Labor; Uberization of Labor.

\footnotetext{
1 Graduação em Turismo (UFPE) e em Ciências Econômicas (UFRPE). Especialização em Gestão e Políticas Ambientais pela UFRPE. Mestrado em Geografia (UFPE).

${ }^{2}$ Graduada, mestra e doutora em Economia (UFPE). Professora da Universidade Federal Rural de Pernambuco - UFRPE
} 


\section{INTRODUÇÃO}

Os diferentes contextos transacionais da geopolítica, globalização e financeirização das relações de poder, e as profundas transformações tecnológicas com forte impacto nas relações laborais, são elementos constituintes da economia global. Neste sentido, no capitalismo contemporâneo, de acordo com Antunes (2018), as novas formas de extração de mais-valia do trabalho, incluindo o trabalho digital, fazem parte dos processos de reorganização do mundo do trabalho. Este movimento de reestruturação não se dá de maneira uniforme no mundo, tampouco nas dinâmicas internas de cada país, sendo um dos resultados, a intensificação da informalidade.

Segundo a OIT (2019), o surgimento das plataformas digitais de trabalho configura-se como uma das principais transformações do mundo do trabalho, na última década. Este novo modelo de emprego modificou as formas de organização do trabalho, e teve como estrutura a possibilidade de dar aos trabalhadores a oportunidade de gerenciar e controlar o próprio tempo de trabalho. Contudo, os riscos inerentes de dedicação a este tipo de trabalho abordam fatores que contradizem esta autonomia laboral, tais como as condições de trabalho, a baixa proteção social e outros benefícios, e quais as motivações reais para ingresso nesta modalidade de trabalho.

No Brasil, a taxa de informalidade tem se mantido elevada no período recente. Em 2019, a taxa atingiu o valor mais expressivo dos últimos anos, 41,3\%. No primeiro trimestre de 2020, a taxa foi de 39,9\%, já no trimestre móvel de março-abril-maio, sob incidência das medidas restritivas de isolamento social devido a pandemia de Covid19, a taxa foi de $37,6 \%$ (IBGE, 2020).

Segundo a ONU (2020), devido às características da América Latina de profunda desigualdade social, sistemas fragilizados de proteção social e de saúde, os impactos decorrentes da pandemia de Covid-19 serão ainda mais fortes que em outras partes do mundo. O organismo prevê drástica redução do PIB regional, expansão do desemprego e da informalidade, e estima um aumento expressivo do número de pessoas na pobreza e na extrema pobreza, passando de 73 milhões para aproximadamente 326 milhões de pessoas. Como a região já vinha imersa em crises políticas e estagnação econômica, o aumento das desigualdades pode ocasionar 
retrocessos no campo dos direitos humanos e das bases democráticas, provocando crises sociais.

Em decorrência do processo de urbanização e industrialização brasileira, a partir da década de 1980 foi notada, de forma mais acentuada, a explosão de atividades comerciais consideradas informais nos grandes centros urbanos. Com a expansão do comércio urbano, as calçadas e ruas tornaram-se mercados de rua, e diversas ações públicas descentralizadas, principalmente vinculadas aos planos municipais e estaduais de desenvolvimento urbano, tentaram conter 0 avanço desenfreado das atividades, assim como buscaram organizá-las (BARROS et. al., 2009). Outra ação recente, instituída em âmbito federal, foi a possibilidade de formalização de trabalhadores informais, através do programa de Microempreendedor Individual (MEI).

Em contextos de crise econômica, a relevância do papel do governo é ainda maior. Cabe a ele, de forma assertiva, a elaboração e aplicação de políticas públicas e medidas emergenciais voltadas para o crescimento econômico com inclusão social, visando o desenvolvimento socioeconômico, a promoção do bem-estar social e a redução das desigualdades. Esse é o viés que permite transformações na estrutura ocupacional do país que implicam em avanços sociais, valorizando a classe trabalhadora que ocupa a base da pirâmide social.

Com os primeiros casos notificados em fevereiro de 2020, a pandemia de Covid-19 se alastrou de forma acentuada e descontrolada no país. Por questões sociais e econômicas grande parte da população não pôde seguir as medidas de isolamento social necessárias, sobretudo os trabalhadores mais pobres e em ocupações com baixa proteção social. Segundo o IBGE (2020), no trimestre móvel março-abril-maio, o nível de ocupação no país foi de apenas $49,5 \%$. O que retrata que menos da metade da população em idade de trabalhar estava ocupada no período em questão, evidenciando a quantidade expressiva de pessoas sem fonte de renda segura do trabalho.

As dinâmicas recentes do mercado de trabalho brasileiro têm evidenciado a questão da informalidade como uma das principais características. As transformações voltadas para a modernização trabalhista têm culminado em aprofundamento da precarização do mercado de trabalho, e neste contexto de expansão do trabalho informal e de subempregos que os entregadores por aplicativos. No que concerne à criação de postos de trabalho precários como caminho de diminuição da acentuada 
taxa de desemprego, isto por si só, não só não tem fomentado a economia, como tem servido para redução dos rendimentos da base da classe trabalhadora. De forma a contribuir, em certa media, para o aumento dos níveis de desigualdade social, com o crescimento da concentração de renda.

\title{
2. INFORMALIDADE E PRECARIZAÇÃO DO MERCADO DE TRABALHO NO BRASIL: DINÂMICAS RECENTES
}

No Brasil, assim como em outros países, a questão conceitual de informalidade é múltipla e diversa, bem como a definição objetiva de atividade econômica informal (NOGUEIRA, 2016; PEREIRA E CABRAL, 2019). Ainda segundo Nogueira (2016), a partir da década de 1970, o setor informal tem sido palco de debates pela significância na oferta ocupacional e de oportunidades de geração de rendimentos. As diversas abordagens partem, primeiramente, de duas premissas para a caracterização do setor: a atividade econômica informal e o trabalho informal.

De acordo com o IBGE (2020), são consideradas pertencentes ao setor informal, as

\begin{abstract}
...unidades econômicas que produzem bens e serviços com o principal objetivo de gerar ocupação e rendimento para as pessoas envolvidas, operando, tipicamente, com baixo nível de organização, com alguma ou nenhuma divisão entre trabalho e capital como fatores de organização, e em pequena escala, sendo ou não formalmente constituídas.
\end{abstract}

Cacciamali (2007 apud NOGUEIRA, 2016, p.12) traz outra definição relevante sobre a organização de produção no setor informal:

(i) o produtor direto é o possuidor dos instrumentos de trabalho e/ou do estoque de bens necessários à realização de seu trabalho, e se insere na produção como patrão e empregado, simultaneamente; (ii) o produtor emprega a si mesmo e pode lançar mão de trabalho familiar ou de ajudantes como extensão do seu próprio trabalho; o proprietário obrigatoriamente participa de maneira direta da produção e da direção do negócio; (iii) o produtor direto vende seus serviços ou mercadorias, o ganho é utilizado, principalmente, para consumo individual e familiar e para a manutenção da atividade econômica, e mesmo que o indivíduo aplique seu dinheiro com o sentido de acumular, a forma como se organiza a produção, com apoio no próprio trabalho, em geral não lhe permite tal acumulação; (iv) a atividade é dirigida pelo fluxo de renda que fornece ao trabalhador e não por uma taxa de retorno competitiva. 
Há dificuldades em dimensionar o tamanho real da informalidade na economia brasileira, além disto, Nogueira (2016) aponta para a existência da semiformalidade, em que economia formal e informal se articulam e se complementam. E este processo se intensifica na atual fase do capitalismo, em âmbito mundial. Segundo Filgueiras et. al. (2018), Krein e Oliveira (2018), os processos de reestruturação produtiva e de reorganização das relações de trabalho marcam a fase recente do capitalismo. Ainda que o processo se dê de maneira heterogênea entre os países, e também dentro de cada um, dentre as características que compõem a dinâmica estrutural do mercado de trabalho, em âmbito mundial, tem-se: expansão do desemprego tecnológico, crescente precarização das relações laborais, como o aumento das jornadas de trabalho e da informalidade.

Sobre a dinâmica recente da economia brasileira, Carvalho (2018) e Nassif (2018) apontam que as políticas econômicas adotadas, sobretudo, entre 2006 e 2010 levaram ao forte crescimento econômico no período, em contrapartida, as adotadas entre 2011 e 2018, levaram a desaceleração e a crise econômica, iniciada me 2015, aprofundada pela crise política. Na primeira fase retratada, o modelo de crescimento econômico esteve atrelado à elevação do consumo das famílias, decorrente da melhoria da distribuição de renda no país. Para isto, o papel de Estado foi relevante no que tange às políticas sociais ${ }^{3}$ e aos investimentos públicos em infraestrutura para captação de investimentos privados. Já a segunda fase foi marcada pela adoção de políticas fiscais expansionistas, via isenções fiscais e tributárias, e de choques monetários, bem como amplas reformas da legislação trabalhista, como caminho de enfrentamento da recessão econômica e estímulos à classe empresarial.

Contudo, Nassif (2018), alerta que o modelo adotado na primeira fase não teria sido sustentado a longo prazo, devido a um conjunto de fatores, quais sejam: taxas de juros reais elevadas, sobrevalorização da moeda nacional em termos reais, baixo desempenho do setor industrial, relacionado à falta de mudanças estruturais e de diversificação produtiva, além de não estar atrelado ao dinamismo do setor terciário.

Para além das divagações acerca dos cenários que seriam vivenciados, é sabido que a crise pós 2015 e a lenta recuperação da economia brasileira nos anos seguintes teve desdobramentos profundos para o mercado de trabalho, como a elevada taxa de desocupação, conforme exposto na Tabela 1. O avanço da

${ }^{3}$ Programas de transferência de renda, como o Bolsa família e política de aumento real do salário mínimo. 
precarização das relações laborais, traduzido, por um lado, pelo aumento da informalidade e da subocupação por insuficiência de horas trabalhadas, e por outro, pela criação de novas e mais precárias formas de vínculos no setor formal, através das leis que flexibilizam as relações laborais, como a Lei da Terceirização (13.429/2017) e, sobretudo, da Reforma Trabalhista (13.467/2017), que implicaram em redução de direitos trabalhistas individuais e coletivos.

Tabela 1 - Taxa de desocupação - Brasil - 2015/2020

\begin{tabular}{lcccccc}
\hline & $\mathbf{2 0 1 5}$ & $\mathbf{2 0 1 6}$ & $\mathbf{2 0 1 7}$ & $\mathbf{2 0 1 8}$ & $\mathbf{2 0 1 9}$ & $\mathbf{2 0 2 0}$ \\
\hline Dez-jan-fev & 7,4 & 10,2 & 13,2 & 12,6 & 12,4 & 11,6 \\
Jan-fev-mar & 7,9 & 10,9 & 13,7 & 13,1 & 12,7 & 12,2 \\
Fev-mar-abr & 8,0 & 11,2 & 13,6 & 12,9 & 12,5 & 12,6 \\
Mar-abr-mai & 8,1 & 11,2 & 13,3 & 12,7 & 12,3 & 12,9 \\
\hline
\end{tabular}

Fonte: adaptado de IBGE (2020). Nota: somente os dados hachurados são comparáveis

Portanto, ainda que o ano de 2019 tenha sinalizado um comportamento mais favorável do mercado de trabalho, tomando por base apenas a geração de empregos, este continua caracterizado por altos índices de desocupados, subocupados, desalentados e informais, conforme apontam os dados do IBGE. O que se traduz em contextos sociais bastante adversos, com aumento da concentração de renda, das desigualdades e da pobreza. Como advertem Menezes e Almeida (2018), o desemprego acentuado e a criação de postos de trabalho precários, cujos rendimentos são baixos, produzem efeitos nefastos na distribuição de renda, contribuindo para o aumento das desigualdades sociais, já tão acentuadas no país.

De acordo com Cacciamali (2000 apud PEREIRA E CABRAL, 2019), a informalidade configura-se como um processo de transformações estruturais econômicas e sociais, que modificam também as relações produtivas e de trabalho, com predominância para duas categorias de trabalhadores: os assalariados sem registro formal, inseridos em vínculos que burlam a legislação trabalhista e, portanto, excluem do rol de garantias sociais; e os trabalhadores por conta própria, representados pelo chamado autoemprego como meio de garantia de renda e de subsistência.

Braga (2012), ao discorrer sobre o moderno proletariado precarizado brasileiro, define-o como a fração de trabalhadores com os piores rendimentos e a mais explorada do proletariado urbano e dos trabalhadores agrícolas, de forma que o conceito de precariado compreende as populações flutuante, latente e estagnada: a 
primeira é formada por trabalhadores sazonais e aqueles com funções temporárias; a segunda é composta por trabalhadores à espera de uma oportunidade; e a última, por trabalhadores que exercem funções deterioradas e mal pagas.

Em paralelo aos indicadores de monitoramento do mercado de trabalho brasileiro, pode-se dizer que englobam os trabalhadores informais, intermitentes, desocupados, desalentados e subocupados. O que condiz com tendências do mercado de trabalho brasileiro das últimas décadas, quais sejam: baixos salários, alta rotatividade e terceirização.

No que diz respeito ao comportamento do mercado de trabalho brasileiro durante a pandemia, como era de se esperar, a taxa de desocupação ${ }^{4}$ tem mantido a tendência de crescimento no país. A comparação do trimestre março-abril-maio em relação ao trimestre anterior mostra expansão de 1,2 p.p., e em relação ao mesmo período de 2019, aumento de 0,6p.p. A Tabela 2 a seguir mostra que o nível de ocupação ${ }^{5}$ pela primeira vez nos últimos anos, considerando o recorte temporal do período de crise econômica do país, ficou abaixo de 50,0\%, expresso em um recuo de 5,0 p.p. em relação ao trimestre anterior. O que demonstra que menos da metade da população em idade de trabalhar estava ocupada no período.

Tabela 2 - Nível de ocupação - Brasil - 2015/2020

\begin{tabular}{lllllll}
\hline & $\mathbf{2 0 1 5}$ & $\mathbf{2 0 1 6}$ & $\mathbf{2 0 1 7}$ & $\mathbf{2 0 1 8}$ & $\mathbf{2 0 1 9}$ & $\mathbf{2 0 2 0}$ \\
\hline Dez-jan-fev & 56,4 & 55,1 & 53,4 & 53,9 & 53,9 & 54,5 \\
Jan-fev-mar & 56,2 & 54,8 & 53,1 & 53,6 & 53,9 & 53,5 \\
Fev-mar-abr & 56,3 & 54,6 & 53,2 & 53,6 & 54,2 & 51,6 \\
Mar-abr-mai & 56,2 & 54,7 & 53,4 & 53,6 & 54,5 & 49,5 \\
\hline
\end{tabular}

Fonte: adaptado de IBGE (2020). Nota: somente os dados hachurados são comparáveis.

O aumento do número de desalentados ${ }^{6}$ (5,4 milhões), 15,3\% em relação ao trimestre anterior, é outro indicativo de deterioração do mercado de trabalho no Brasil. Em parte, a medida de distanciamento social, fez com as pessoas deixassem se deslocar em busca de emprego, incrementando a massa de desalento. Ao comparar a elevação da força de trabalho potencial, formada por pessoas não ocupadas, com dados com o mesmo período do ano anterior, o aumento foi de quase 40\%. Em 2019 o total era de 8,3 milhões e em 2020, 11,8 milhões, como podem ser observados na Tabela 3 a seguir.

\footnotetext{
4 Mede a população desocupada em relação à população na força de trabalho.

5 População ocupada em relação à população idade de trabalhar.

${ }^{6}$ Pessoas que, por motivos diversos, desistiram de procurar trabalho remunerado.
} 
Tabela 3 - Medidas de monitoramento do mercado de trabalho (em \%)

\begin{tabular}{lc|c|c}
\hline Variáveis & Mar-Abr-Maio & Dez-Jan-Fev & \multicolumn{1}{l}{ Mar-Abr-Maio } \\
& $\mathbf{2 0 2 0}$ & $\mathbf{2 0 2 0}$ & $\mathbf{2 0 1 9}$ \\
\hline Taxa de desocupação & 12,9 & 11,6 & 12,3 \\
Taxa composta de subutilização & 27,5 & 23,5 & 25,0 \\
Taxa de desalento & 5,2 & 4,2 & 4,4 \\
\hline
\end{tabular}

Fonte: elaboração própria a partir dos dados da Pnad Contínua, IBGE (2020)

Durante a pandemia, a perda de renda tem sido mais expressiva para os trabalhadores informais, sobretudo para aqueles cuja atividade se insere nos segmentos de comércio e serviços. De acordo com o IBGE (2020), os setores com pior remuneração e maior grau de informalidade foram os mais atingidos, tais como alimentação e serviços relacionados a atividades de aglomeração, como turismo e lazer. Conforme Carvalho (2020), no que concerne ao impacto da pandemia nos rendimentos dos trabalhadores, os grupos mais atingidos foram os dos trabalhadores por conta própria e os trabalhadores do setor privado sem carteira assinada, cuja renda ficou em torno de $60 \%$ e $76 \%$ dos seus rendimentos habituais, respectivamente.

Em contextos de elevado desemprego, uma parcela significativa dos trabalhadores busca no trabalho informal ou por conta própria uma alternativa de subsistência, este tipo é chamado de empreendedorismo por necessidade. Em 2018, $37 \%$ que possuíam um negócio próprio o fizeram nesta modalidade, em 2019, a taxa foi ainda maior, 43\% (MIRANDA, 2019). A autora aponta ainda que em 2019 havia cerca de 12,7 milhões de empreendedores formalizados, dos quais 35,3\% estavam inseridos em ocupações sem um estabelecimento fixo de trabalho (em local fixo, fora de loja e porta a porta, postos móveis ou ambulantes), evidenciando o trabalho precarizado neste segmento.

É possível afirmar que perfil majoritário do empreendedor no Brasil é composto, na verdade, por trabalhadores que buscam formas de subsistência fora do trabalho formal. Sem acesso a capital e a financiamento, a construção de um negócio estruturado é algo romantizado. Diante da crise provocada pela pandemia e das medidas de isolamento, muitos empreendedores buscaram estratégias de sobrevivência dos próprios negócios, com ampla recorrência ao sistema de entregas em domicilio, e aos trabalhadores por aplicativos.

Nesta perspectiva, é importante pontuar que por trabalho uberizado tem-se uma nova forma de organização do trabalho, onde a classe trabalhadora arca com os 
riscos e custos da profissão. Além de ter apropriada sua força de trabalho, uma parcela significativa tem apropriados também os próprios bens físicos, como meios de transporte e equipamentos de trabalho e de segurança, e o tempo de descanso, haja vista a intensa jornada de trabalho. Portanto, decorrente do processo de financeirização e digitalização do trabalho, a uberização informaliza o trabalho e dissocia a mão de obra do sujeito, tornando-o irrelevante e desprotegido de direitos sociais e individuais do trabalho.

\section{MODERNIZAÇÃO TRABALHISTA NO BRASIL E A QUESTÃO DA INFORMALIDADE DURANTE A PANDEMIA}

A forma como a relação capital/trabalho se expressa, atualmente, ditando a tendência mundial de flexibilização do trabalho e novas de organização do trabalho, fundamenta a exploração da classe trabalhadora, balizada no discurso de modernização trabalhista.

Como apontam Portes e Hoffman (2003 apud BALTAR E ROLIM, 2018), uma das especificidades dos países latino-americanos é o alto nível de desigualdade de renda, devido, em certa medida, ao expressivo contingente de pessoas fora do mercado formal de trabalho, que exercem atividades de subsistência ou nãoregulamentadas, cujos rendimentos são relativamente baixos. São trabalhadores não assalariados ou por conta própria, ou ainda assalariados no setor informal, em ocupações que possuem baixa proteção social e baixos salários.

Conforme Pereira e Cabral (2019), a evolução do trabalho no Brasil é marcada por um amplo processo de desestruturação do mercado, sob a hegemonia neoliberal, e tem como características o desmonte da regulação das medidas sociais e protetivas concomitante a diminuição do controle do Estado sobre o setor privado, no que diz respeito à desregulamentação da proteção social do trabalho. Neste contexto, e diante da crise econômica vivenciada nos últimos anos, o desemprego e a informalidade tem aumentado significativamente.

Ainda segundo esses autores, as intensas transformações econômicas e do trabalho, a partir da década de 1980, com a configuração de novos padrões tecnológicos, organizacionais e produtivos, possibilitaram que o capital amplie e diversifique seu processo de acumulação. Como principais estratégias, tem-se a 
financeirização global, a descentralização e o aumento da automação produtiva. $\mathrm{O}$ que acarretou em mudanças, também, nas relações sociais e laborais.

No que tange ao processo de estruturação recente das medidas modernizadoras do mercado de trabalho brasileiro, em 2017, a estrutura normativa que regula as relações de trabalho no Brasil foi profundamente alterada pela entrada em vigor de duas leis: a Lei ํㅜ 13.429, conhecida como Lei da Terceirização, que instituiu, dentre outras medidas, a terceirização irrestrita das atividades empresariais. E a lei da Reforma Trabalhista, a Lei № 13.467, responsável pela alteração de vários artigos da Consolidação das Leis do Trabalho (CLT). Tais como a flexibilização das jornadas laborais e a inserção de novas modalidades de trabalho, dentre outras medidas.

Configuram-se como uma série de ações que, em certa medida, contribuem para a continuação da elevada expressão da informalidade e da destruição do sistema protetivo do trabalho em seu conjunto, através da possibilidade de contratação em condições precarizantes, tais como o trabalho intermitente, por tempo parcial, a prestação de serviços autônomo, a terceirização irrestrita, além da fragilização da ação sindical e de acesso à Justiça do Trabalho. Em que pese o papel do Estado de agente regulador e protetor, a Reforma Trabalhista de 2017, em certa medida, tem servido como promotora de formas de informalização dentro do sistema do trabalho formal.

Neste contexto, tem-se a expansão da informalidade como um dos desdobramentos do cenário de desregulamentação trabalhista e de baixo dinamismo econômico. Primeiro, é preciso pontuar que proteção social e formalização não são, necessariamente, complementares. Isto porque o processo de formalização não garante que as ocupações estejam, de fato, revestidas de pressupostos de trabalho decente e com condições dignas ao trabalhador. Entretanto, ainda que esteja em curso um processo de baixo mecanismo protetivo do emprego formal, a correlação com a outra dimensão, a dos trabalhadores às margens do sistema de proteção, tornase ainda mais agravada. Segundo, emprego ou direitos não devem ser questões contrapostas, visto que desregulamentação e flexibilização não garantem a diminuição da informalidade, tampouco se traduz em melhoria dos indicadores de emprego e renda. 
No tocante à política mundial e à economia globalizada, os processos de estagnação econômica e a guerra comercial entre as grandes potências já vinham afetando as economias dos países, e no cenário trazido pela pandemia, os países buscam proteger-se, e isso se traduz, em maior ou menor impacto, nas dinâmicas delas e de outros países. Neste sentido, a forma como as nações vão conduzir o processo de reorganização econômica, interna e externamente, ameniza ou aprofunda os efeitos da crise decorrente da pandemia de Covid-19.

Como medida para amenizar os impactos econômicos da crise sanitária, entrou em vigor a lei Emergencial de Manutenção do Emprego e da Renda (lei no 14.020/2020) que autoriza acordos individuais entre empregado e empregador para redução das jornadas de trabalho e salários, e para a suspensão de contratos de trabalho, amparados pelo pagamento de um Benefício Emergencial, com base no seguro-desemprego, para complemento dos rendimentos.

Não obstante que esteja voltada para o emprego formal, a suspensão e a redução de salários e jornada de trabalho, como medida de manutenção dos postos de trabalho e do rendimento dos trabalhadores, via desoneração e redução de custos para o empregador, tal política pode implicar em desassistência ao trabalhador, pois apesar de estar vinculado a uma estabilidade provisória, em tempos de fortes incertezas para o futuro, pode não se traduzir em benefício duradouro e efetivo para a classe trabalhadora.

Neste sentido, o contingente de pessoas desempregadas e ocupadas em atividades precárias pode seguir a tendência de expansão que já se mantinha desde antes da pandemia. E nesta perspectiva, a fragilidade é ainda maior para os já excluídos do sistema protetivo do trabalho, que vivem à margem da economia e são invisibilizados pela sociedade e pelo Estado. Por isso, a questão da desigualdade de renda é um dos pontos cruciais ao pensar políticas de proteção social no Brasil.

Assim, é possível que na relação informalidade e pandemia, os trabalhadores por conta própria, visto que não desfrutam de mecanismos de proteção social, sejam mais vulneráveis aos impactos econômicos, além disto, esta modalidade tende a ter um crescimento substancial como estratégia de sobrevivência adotada, inclusive, pelos trabalhadores cujo emprego formal seja perdido ou que encontrem dificuldade de inserção no mercado de trabalho. Neste contexto estão inseridos os trabalhadores por aplicativos, cuja uberização do trabalho é, na verdade, uma nova forma de informalização laboral e de organização do trabalho no capitalismo. 
A recente dinâmica do mercado de trabalho e as medidas trabalhistas implementadas como alternativa para dinamização da economia e geração de empregos, porém pautadas em redução de direitos e de custos trabalhistas, tem apresentado como resultado o aumento substancial do desemprego, da informalidade e a intensa precarização do trabalho. Tem-se de um lado o atendimento das premissas capitalistas, a expansão dos ideais de autorregulação do mercado e o, do outro, a desconstrução de direitos sociais e trabalhistas e o enfraquecimento da organização sindical.

Uma das explicações possíveis é dada por Filgueiras et. al. (2018 p. 128), ao afirmar que

esse processo tem ocorrido tanto pela substituição do assalariamento com carteira por modos informais, precários e ilegais de contratação pelos empregadores, quanto pela ampliação de ocupações efetivamente por conta própria como forma imediata de sobrevivência.

Os autores alertam ainda que estas formas de contratação têm implicado em piores formas de precarização do trabalho em todo o mundo. E que a expansão da contratação, no Brasil, de trabalhadores autônomos e por trabalho intermitente ${ }^{7}$ é a maneira de legitimação do uso de formas precárias de inserção ocupacional pelos empregadores, fato que tem ocorrido em âmbito mundial, e se traduz na extrema mercadorização do trabalho e da subordinação da vida à dinâmica do capital.

A Lei da Reforma Trabalhista anuncia, nos artigos 442 e 443 da Consolidação das Leis do Trabalho (CLT), que a contração do autônomo para prestar serviços não gera vínculo empregatício, e que o contrato individual do trabalho pode ser acordado verbalmente ou por escrito, de maneira que tais direcionamentos servem para proteger as empresas de eventuais litígios trabalhistas. Quanto ao trabalho intermitente, a lei favorece a classe empresarial ao desonerar a folha de pagamento, posto que não há um custo fixo, já que o trabalhador recebe apenas pelo tempo de serviço efetivamente trabalhado, tornando o tempo inativo de trabalho, em tempo não remunerado. No tocante ao depósito do FGTS, o empregador fica obrigado a fazer o

7 Considera-se como intermitente o contrato de trabalho no qual a prestação de serviços, com subordinação, não é contínua, ocorrendo com alternância de períodos de prestação de serviços e de inatividade, determinados em horas, dias ou meses, independentemente do tipo de atividade. 
recolhimento com base nos valores pagos mensais, assim, para os meses de inatividade do trabalho, não há recolhimento do FGTS.

Desta maneira, delega-se ao trabalhador a complementação mensal dos rendimentos mínimos para subsistência familiar, bem como da contribuição previdenciária para fins de aposentadoria, assim como amplia 0 arbítrio do empregador sobre a gestão do tempo de trabalho. Neste sentido, estas formas de contratação elevam os riscos às incertezas, às condições de vulnerabilidade e de superexploração do trabalho.

Ainda sobre o contrato intermitente, conforme Menezes e Almeida (2018), a inserção desta modalidade de contrato teve como principal fundamento o argumento de que através dele seria possível regularizar trabalhos informais, além de ampliar a oferta de emprego e reduzir as taxas de desemprego, contribuindo, desta maneira para o desenvolvimento da economia brasileira.

Entretanto, esta forma de prestação de serviço, por ocorrer de forma descontinuada, com alternância entre períodos de trabalho e de inatividade, sem que haja percepção de rendimentos para o período inativo e sem possibilidade de planejamento prévio da rotina de trabalho para subsistência, acentua as condições laborais precarizadas, devido às incertezas e a impossibilidade de gestão do próprio tempo. Pois, como advertem Menezes e Almeida (2018), a dependência da convocação do empregador para que haja remuneração pelas horas efetivas de trabalho, tornará o trabalhador sempre disponível aos requisitos do empregador, no intuito de manutenção da relação laboral, além de inviabilizar o planejamento do tempo livre e de investimentos pessoais futuros.

Neste sentido, a incerteza e a instabilidade da relação laboral retomam a ideia da mão de obra enquanto mercadoria, bem como desrespeitam a limitação da jornada de trabalho, posto que esta inclui o tempo à disposição do empregador. Como forma de auferir rendimentos suficientes para o próprio sustento, a vinculação a mais de um empregador também expõe o trabalhador a diversas cargas horárias e jornadas de trabalho sem limites. Para Carelli (apud MENEZES E ALMEIDA, 2018), a regulação do tempo laboral é o centro das relações trabalhistas, uma vez que a partir dele é estipulado o preço de troca entre empregado e empregador.

Outros princípios apontados por Menezes e Almeida (2018), são o da onerosidade, visto que a remuneração mensal do trabalho é vinculada apenas às horas efetivamente trabalhadas; da alteridade, que se refere à assunção dos riscos 
do trabalho, visto que este modelo de contrato transfere os riscos da atividade para o empregado, e na hipótese de baixa demanda, tem-se um trabalho sem remuneração; e o da proteção, pois não garante que o empregado será convocado a quantidade de horas referentes para ganhos de, ao menos, um salário-mínimo. Para este último princípio, os autores citam o caso da legislação italiana, que impõe um tipo de indenização mensal de disponibilidade ao empregado, referente ao tempo à disposição do empregador.

Para Peduzzi (2020), as reformas trabalhistas que vem ocorrendo na maioria dos países ocidentais, buscam, sobretudo, criar mecanismos legais de ação protetiva aos trabalhadores informais, invisíveis do rol de normas que regulam e protegem as relações laborais formais. E por isso, em uma economia complexa, é fundamental a garantia da segurança jurídica pelo Estado, para que seja possível construir um futuro próspero e com justiça social.

A criação do Programa de Microempreendedor Individual (MEI), a partir da promulgação da Lei Complementar 128/2008, passou a vigorar no país em julho de 2009, no intuito de formalizar trabalhadores informais e autônomos. A possibilidade de regularização e formalização de diversos profissionais às margens da legislação, balizada na conquista de benefícios ${ }^{8}$, amparo legal e segurança jurídica, fundamentase no discurso apologético do empreendedorismo como caminho de autonomia financeira e de liberdade profissional. Neste sentido, a autonomia é construída através da individualização das relações laborais e do trabalho por conta própria, com o status social de pequeno empresário. Atualmente, mais de 8,4 milhões de pessoas estão formalizadas como MEI, no Brasil, e são mais de 460 modalidades ocupacionais relacionadas aos setores de serviço, comércio ou indústria.

Como adverte Nogueira (2018), posto que o programa do MEl é subordinado à Lei Geral das Micro e Pequenas Empresas (MPEs), Lei Complementar ㄲo123/2006, a formalização esbarra no arranjo federativo do país, que impõe diversas barreira à simplificação de licenças de funcionamento, visto que para várias atividades há exigências municipais, estaduais e federais a serem atendidas, tais como alvarás e

\footnotetext{
${ }^{8}$ Dentre os benefícios dos MEls, tem-se: contribuição de valor menor para a Previdência, auxíliodoença, auxílio-maternidade, aposentadoria, realização de empréstimos com taxas de juros reduzidas, emissão de notas fiscais, facilidade na abertura de contas, acesso à crédito, possibilidade de terceirização do serviço, pagamento simplificado de tributos e impostos.
} 
licenças. O que expõe a necessidade de desverticalização e integração das políticas públicas.

Outra questão pertinente levantada pelo autor é o possível processo de "desassalariamento", a partir do qual um trabalhador com vínculo de empregado assalariado transformar-se em MEl, e passa a atuar como prestador de serviços para a própria empresa. Ponto reforçado pela Lei da Terceirização (lei 13.429/2017) e da Reforma trabalhista (lei 13.467/2017), que fomenta novas modalidades de trabalho e autoriza a terceirização das atividades-fim das empresas. O que, segundo Krein e Oliveira (2019), tem resultado em avanço da precarização das relações laborais. E nesta perspectiva, a economia informal tem encontrado na própria legislação que regula as relações trabalhistas no país, formas de funcionamento que continuam a precarizar o trabalho e alavancar a desigualdade social.

Considerando o baixo dinamismo da economia, o cenário do mercado de trabalho pós reforma trabalhista é de poucos indícios de recuperação, principalmente porque a leve queda do desemprego e do desalento, em 2019, esteve atrelada à geração de postos de trabalho no setor informal. $O$ que demonstra que para os estratos sociais mais vulneráveis, a realidade de insegurança, instabilidade e baixa proteção social tem se mantido constante.

Apesar das condições sociais e econômicas, Braga (2012) aponta como caminhos de resistência aos avanços da desestruturação do mercado de trabalho e do desmonte de direitos trabalhistas, a necessidade de auto-organização do precariado com poder decisório nas bases, e sua prática política na luta pela efetivação de direitos trabalhistas, bem como de ampliação dos mesmos, através da mobilização coletiva.

Com os impactos socioeconômicos decorrentes da pandemia de Covid-19, o Governo Federal estabeleceu medidas de auxílio financeiro para a população mais vulnerável, aqueles que durante o período de isolamento social não poderiam manter o próprio sustento. Assim, com previsão total estimada em $\mathrm{R} \$ 257,2$ bilhões, o Programa de Auxílio Emergencial é um programa de transferência direta e temporária de renda aos estratos sociais que vivem à margem da economia, e engloba os beneficiários do Programa Bolsa Família, os inscritos no Cadastro Único para Programas Sociais do Governo Federal (Cadúnico), os trabalhadores desempregados, informais, com contrato de trabalho intermitente e os microempreendedores individuais. 
A partir de diversos requisitos para aptidão ao recebimento do auxílio, o objetivo foi priorizar a assistência financeira àqueles que não possuem renda fixa mensal. Ao dar autonomia de escolha, através transferência direta dos recursos para as famílias, o programa permite a diversificação do consumo das famílias e incrementa a economia. É importante destacar que aproximadamente $70 \%$ do PIB brasileiro advém do consumo das famílias. E exatamente por isto, o programa tem um forte impacto positivo no PIB, contribuindo para aliviar o impacto econômico da crise. Outro ponto que merece destaque é o efeito regionalizado do auxílio, uma vez que os maiores beneficiários dos programas sociais que englobam o auxílio emergencial residem nas regiões norte e nordeste, que são as mais afetadas pelo desemprego, possibilitando um maior impacto no PIB dos municípios nortistas e nordestinos.

De acordo com a ONU (2020), no que concerne às recomendações para a região da América Latina e o Caribe, no curto prazo, a criação de mecanismos para implantação e manutenção de uma renda básica emergencial é imprescindível para amenizar os efeitos da crise econômica para os mais vulneráveis e os trabalhadores informais. E as medidas de auxílio financeiro devem ser complementadas, quando necessário, com outros programas de combate à fome e à extrema pobreza. Além disto, as estratégias de enfrentamento devem ser acompanhadas de mudanças estruturais e fiscais para o fomento de um sistema tributário fortalecido e progressivo, visando uma maior redistribuição de renda e a evasão fiscal.

\section{UBERIZAÇÃO DO TRABALHO: CONSIDERAÇÕES ACERCA DOS ENTREGADORES POR APLICATIVOS}

As mudanças do mundo do trabalho, as novas formas de organização do trabalho e as transformações produtivas, sobretudo de cunho das inovações tecnológicas, ocasionando forte expansão das atividades de serviços por aplicativos, tem despontado como tendência global. De acordo com a OIT (2019), o surgimento das plataformas digitais são uma das mais expressivas transformações no último decênio, resultantes dos avanços tecnológicos e atreladas ao crescimento do uso da Internet. Em contrapartida, o trabalho que geram são semelhantes a formas antigas de exploração da força de trabalho, cuja ferramenta digital serve de intermediária.

Ainda segundo a organização, as plataformas se dividem em basicamente dois tipos: plataformas em linha, ou crowdwork, através das quais o trabalho e terceirizado 
mediante convocatórias abertas a um público disperso geograficamente. E os aplicativos móveis com geolocalização, por meio dos quais o trabalho se desenvolve em um local específico de circulação de cada trabalhador. Neste segundo tipo, por meio dos aplicativos, os trabalhadores recebem instruções para prestação do serviço, que geralmente são vinculados aos setores de transporte de passageiros, entrega de comidas e outras mercadorias, serviços domésticos e serviços de cuidado. Em ambos os casos, são modalidades de trabalho que oferecem às empresas e clientes, acesso a uma força de trabalho extensa e flexível.

Assim, segundo Coelho (2019), as transformações promovidas pela Revolução Digital, serviram para introduzir esta modalidade de trabalho via aplicativos, na economia, através de empresas de tecnologia cuja função, por elas estabelecidas, é apenas conectar negócios, consumidores e trabalhadores, denominados "parceiros". Para a autora, os elementos que configuram esta nova forma de prestação laboral, intensamente utilizada no Brasil, possuem indicativos de subordinação, corroborando a relação empregatícia. Sendo a subordinação o principal traço que define trabalhadores autônomos dos subordinados, dando a estes direitos ao conjunto de direitos e benefícios trabalhistas e de seguridade social.

Conforme aponta Putti (2019), as relações laborais mediadas por aplicativos configuram-se, na atualidade, como a mais intensa força propulsora de geração de empregos precarizados no país. O fato está fortemente atrelado ao aprofundamento da crise econômica, desde 2015, e à destruição sistemática de vagas formais, bem como as alterações nas relações de terceirização das atividades econômicas. Segundo o autor, em 2019, as empresas globais Uber, iFood e Rappi, empregavam juntas cerca de 4 milhões de pessoas no Brasil. Como a empresa Uber foi pioneira, tornou-se mais conhecida e serviu de inspiração para os demais aplicativos. A mesma teve o nome adjetivado como forma de precarização desta nova lógica de organização do trabalho, a chamada "uberização" do trabalho.

Assim, o baixo dinamismo da economia brasileira nos últimos anos, associado a outros fatores também relevantes, como o processo de desregulamentação das relações laborais, implementado pelo governo e com apoio do setor empresarial, e a deterioração do mercado de trabalho, tem contribuído para o crescimento da informalidade, bem como para o fomento de retrocessos no campo dos direitos trabalhistas, perdas de proteção social e mercantilização da força de trabalho. Além 
da construção apologética do trabalho individualizado e precarizado como empreendedorismo.

Conforme apontam Menezes e Almeida (2018, p. 5) a Organização Internacional do Trabalho, em 1919, refutou a ideia de mercadorização do trabalho, e a Declaração Universal dos Direitos Humanos, em 1948, expôs em seu artigo 23, que "todo ser humano que trabalhe tem direito a uma remuneração justa e satisfatória, que Ihe assegure, assim como à sua família, uma existência compatível com a dignidade humana, e a que se acrescentará, se necessário, outros meios de proteção social".

Peduzzi (2019) adverte que, devido às rápidas e profundas transformações no mundo do trabalho na Era da Tecnologia, o Direito do Trabalho precisa constantemente adequar suas normas para atender às novas formas de organização do trabalho, bem como à descentralização produtiva, e proteger trabalhadores e consumidores, oferecendo, desta maneira, segurança jurídica às partes e contribuindo para o desenvolvimento econômico.

A Reforma Trabalhista de 2017 teve entre seus fundamentos regularizar formas de ocupações consideradas ilegais pela CLT, e neste conjunto despontam as relações de trabalho estabelecidas pelos aplicativos. Em um ambiente desregulado de trabalho, as intervenções estatais são necessárias para garantir condições mínimas de trabalho e de proteção social. E diante da ausência ou ineficiência delas, as demandas na Justiça do Trabalho aumentam em busca de reconhecimento de vínculos empregatícios (PUTTI, 2019). Os trabalhadores que prestam serviço por aplicativos estão descobertos do acesso a direitos e benefícios trabalhistas como pagamento de horas extras, intervalos de descanso, férias, recolhimento do FGTS, além daqueles que compões o regime previdenciário, exceto o façam por conta própria, no que concerne apenas à contribuição ao INSS, como MEI.

A pandemia de Covid-19 impôs medidas rigorosas de isolamento social, que afetaram as rotinas e expuseram as condições adversas de várias categorias profissionais, como é o caso dos entregadores por aplicativos. A uberização do trabalho, termo usado para definir novas relações laborais em um contexto tecnológico e de livres acordos, evidencia condições degradantes de trabalho.

Segundo Peduzzi (2020), as restrições sanitárias no intuito de controlar a pandemia tem causado instabilidade econômica no país, ocasionando impactos 
diretos e imediatos no mercado de trabalho e nas relações laborais. E neste cenário, o uso de tecnologias ganha ainda mais intensidade para atender às novas demandas.

Em contraposição ao discurso de que a rentabilidade de uma empresa deva estar atrelada a exploração de uma massa de trabalhadores cuja ocupação se assemelha a um tipo de escravidão digital, é fundamental que haja uma legislação social protetora das relações laborais, para regular toda forma de trabalho. No caso da economia digital, tem-se empresas que operam com maquinário tecno-científicoinformacional bastante desenvolvido, em detrimento de relações precarizadas de trabalho (ANTUNES, 2018).

No rol de ocupações disponíveis para cadastro de $\mathrm{MEl}$, a profissão de entregador é uma delas, sob inscrição na Classificação Nacional de Atividades Econômicas, CNAE 5320-2/02 como serviços de entrega ${ }^{9}$. No que concerne à descrição das atividades realizadas, tem-se de realizar entregas de encomendas em domicílio sob contrato ou não, assim como de mercadorias do comércio varejista e de serviços de alimentação.

Nesta modalidade ocupacional, registrados ou não, estão inseridos os trabalhadores por aplicativos, que correspondem a aproximadamente cinco milhões ${ }^{10}$ de brasileiros. São pessoas submetidas a jornadas de trabalho exaustivas, remuneração baixa, e ausência de proteção social, direitos ou benefícios trabalhistas, como férias, descanso semanal mínimo, $13^{\circ}$ salário. A falsa autonomia dos trabalhadores por aplicativo, expressa na subalternidade e dependência às empresas de aplicativos, configura-se em vinculo de trabalho sem acesso a direitos trabalhistas e previdenciários.

No que tange à forma de entrada às empresas, o registro dos trabalhadores se dá nas próprias plataformas, onde os interessados na prestação do serviço se registram e aderem a um contrato de adesão padronizado, cujas diretrizes afastam garantias trabalhistas, restringem responsabilidades empresariais, bem como indicam as leis aplicáveis à relação laboral (KALLIL, 2019).

\footnotetext{
9 Engloba as seguintes atividades: serviços de coleta de encomendas; distribuição de jornais em domicílios; entrega de medicamentos; entrega de refeições, alimentos para restaurantes; entrega rápida de encomendas por moto boy; entrega de jornais, revistas, catálogos e outras publicações.

10 Dado retirado da entrevista com o pesquisador Felipe Moda, que aponta que as empresas de plataforma digital Uber, iFood, 99 e Rappi contavam com um quadro de mais quatro milhões de pessoas, em 2019. Disponível em https://www.geledes.org.br/uberizados-preludio-da-era-dos-bicos/
} 
Conforme adverte a OIT (2019), atualmente no mundo, grande parte do trabalho em plataformas digitais não há nenhuma regulação normativa da atividade, de maneira que os trabalhadores tem baixo controle sobre as condições de trabalho e periodicidade do mesmo, bem como sobre possibilidades de negociações e reivindicações.

As plataformas digitais de trabalho ligam o prestador de serviços às empresas, e estas aos consumidores finais. As empresas, apesar de não estipularem jornada ou local de trabalho, utilizam o algoritmo para favorecer quem mais trabalha e os mais bem avaliados pelos clientes, e punir aqueles que se desconectam. A remuneração é composta apenas pelo percentual do valor cobrado pelo serviço, e das gorjetas dadas pelos clientes. Tem-se, pois, uma estrutura extremamente perversa de superexploração e mercantilização dos trabalhadores, cujas jornadas de trabalho em pleno século XXI se assemelham, em termos de duração, ao período da Revolução Industrial.

Em termos de circunstâncias laborais e segurança financeira, a OIT (2019) aponta as principais dimensões das condições de trabalho, são elas: remuneração, proteção social, tipo de trabalho, intensidade do trabalho, disponibilidade de trabalho, rejeição da mão de obra e falta de pagamentos, comunicação entre empregados e empregadores, e manuseio da plataforma.

Por sua vez, Kalil (2019) define quatro características principais dos trabalhos por demanda em aplicativos, são elas: (i) baixa autonomia dos trabalhadores acerca da carga horária e da jornada de trabalho; (ii) relação direta entre dependência e precariedade; (iii) gerenciamento algorítmico da força de trabalho; e (iv) acentuada desigualdade econômica entre as partes envolvidas, trabalhadores, consumidores e plataformas.

No que concerne à gestão do tempo de trabalho mediante algoritmos de mão de obra, ela basicamente define o trabalho nas plataformas digitais. Mas já permeava outras formas de trabalho, anteriormente, conforme adverte a OIT (2019). Visto que a partir da década de 1980, muitas empresas passaram a incorporar softwares para otimizar o controle de turnos dos empregados, assim como sistemas automatizados de controle e retirada de mercadorias em depósitos. Contudo, nas plataformas digitais de trabalho, a gestão via algoritmo controla quase todos os aspectos do trabalho. 
Para Coelho (2019), a organização do trabalho e seu controle através de programação algorítmica configuram esta nova modalidade laboral, incumbido da prerrogativa de que dê ao trabalhador certa esfera de autonomia na prestação do serviço. Como a programação por algoritmos representa um conjunto metódico de instruções e cálculos para gerenciar as decisões, aqueles trabalhadores que seguem a programação tem um melhor desempenho, e recebem bonificações, em contrapartida, os que não atendem aos comandos são punidos. De maneira que, criase uma constante sensação de insegurança e de necessidade de disponibilidade total para o serviço, como mecanismo de controle mais eficiente da mão de obra. O que serve para configurar a relação de subordinação entre trabalhador e empresaaplicativo.

Möhlmann e Zalmanson (2017 apud OIT 2019) apontam que a gestão mediante algoritmo possui cinco características principais: delegação do serviço; constante avaliação do desempenho dos trabalhadores através de notas dadas pelos clientes; implementação automática das decisões; interação dos trabalhadores estrita a um sistema computacional enquanto empregador, sem espaço para negociações ou diálogos; pouca transparência de funcionamento, em certa medida, devido às estratégias competitivas do mercado.

Kalil (2019) ressalta que é importante não personificar a ideia do algoritmo, tomando-o como sujeito, não só porque ao representá-lo como mecanismo independente, desconsidera-se o ambiente social e técnico em que está inserido. Mas também porque, ao fazê-lo, se oculta o processo de modulação algorítmica, realizado através de comandos humanos. Assim, a coordenação e o controle da força de trabalho são construídos por meio de conjunto de instruções, bem como o processo de tomada de decisões é definido por parâmetros estabelecidos pela empresa. Neste sentido, no que tange aos processos organizacionais, os algoritmos assumem papéis gerenciais e os códigos modulados exercem tarefas como determinar a cumprimento das atividades e a duração das mesmas, monitorar os trabalhadores e avaliá-los, acelerar o processo de trabalho, dentre outros.

Abílio et. al. (2020) assinalam que não há, atualmente, uma forma precisa de mensurar a quantidade de trabalhadores nesta modalidade, devido à falta de registros. No que concerne aos recortes de raça e gênero, a população é predominantemente masculina, parda e preta, na faixa etária mais comum entre 25 e 44 anos. E a respeito da jornada de trabalho, os autores apontam que antes e durante a pandemia, quase 
$60 \%$ trabalham de 9 horas a 15 horas por dia, e que 77,4\% trabalham entre 6 e 7 dias semanais, o que configura uma jornada intensiva e ininterrupta de trabalho.

Esta nova forma de organização do trabalho fundamenta-se no ideal de liberdade profissional e empreendedorismo, e transfere para os trabalhadores a responsabilidade por criar as próprias condições de trabalho, uma vez que fomenta a valorização do trabalho por conta própria como estratégia de sobrevivência. Segundo Antunes e Braga (2020), a autonomia da prestação de serviço é, na verdade, a individualização da classe trabalhadora e a estruturação do trabalho fora da legislação social do trabalho.

A rentabilidade empresarial advém da exploração da classe trabalhadora com baixo custo social, visto que não há encargos trabalhistas e previdenciários. Como bem definiram Antunes e Braga (2020), tem-se tecnologia de ponta de um lado e, do outro, espoliação de direitos e mercantilização do trabalho. Essa combinação de avanço tecnológico com retrocesso trabalhista se traduz em condições de trabalho degradantes controladas por um algoritmo, que define remuneração, jornada e intensidade do trabalho. Visto que muitos dos entregadores trabalham mais de 12 horas por dia, durante toda a semana. Além do que é um tipo de relação de trabalho em que a classe trabalhadora não tem nenhum poder de negociação com as empresas, e as decisões são totalmente unilaterais a partir das regras e dinâmicas das plataformas.

Tem-se, portanto, uma oferta de empregos temporários e mal remunerados. De acordo com Coelho (2019), através da baixa precificação e da baixa remuneração por hora trabalhada, as empresas buscam o monopólio do mercado, afastando a entrada de empresas concorrentes. Além de garantir o controle do tempo laboral e aumentar a disponibilidade de serviço, pois são necessárias muitas horas de trabalho para a subsistência do trabalhador, o que desfaz a proteção trabalhista no que concerne aos limites de hora de trabalho.

Para a autora, as avaliações dos trabalhadores através das notas e comentários dos clientes é outra estratégia de controle da mão de obra, servindo para gerenciar e verificar o cumprimento da atividade de maneira múltipla e descentralizada. De tal modo que a nota exerce poder sobre a forma de prestação do serviço, podendo retirar ou bloquear o trabalhador da plataforma. 
Kallil (2019) reitera a ideia ao afirmar que o sistema de avaliação desempenha um papel central no controle da força de trabalho. Para tanto, além das opiniões dos clientes, o sistema considera como relevante também o atendimento das políticas da empresa e a velocidade de aceitação para realização de uma nova tarefa. Consoante sirva de instrumento de controle restrito para as empresas, a falta de transparência impossibilita que os trabalhadores saibam com clareza os critérios de avaliação e as regras de funcionamento, que se pauta em um conjunto de incentivos e sanções.

No Brasil, os trabalhadores por aplicativos, que tem tido uma importância substancial em tempos de pandemia devido às medidas de isolamento social, fizeram paralisações nacionais para reivindicar melhores condições de trabalho e proteção à saúde. Os entregadores expuseram a realidade de rendimentos baixos, com ganhos até inferiores ao período anterior à crise, e falta ou insuficiência de equipamentos de proteção individual disponibilizado pelas empresas de aplicativos. Precarizados e submetidos à exploração do trabalho, as condições foram intensificadas durante a pandemia, com risco de adoecimento e sem proteção trabalhista quanto ao fato.

No que tange às transformações do trabalho no período recente, antes da chegada das plataformas de trabalho por aplicativos, a categoria de entrega rápida, por motoboy, era amplamente regulamentada pelo regime celetista, de forma que os trabalhadores tinham vínculo com alguma empresa e, portanto, acesso a uma rede de proteção do trabalho, bem como possibilidade de recebimento de adicional de insalubridade devido aos riscos inerentes à saúde dos trabalhadores.

A OIT (2019) define o trabalho decente como aquele que assegura igualdade de oportunidades e tratamento para mulheres e homens, tem remuneração justa, existe segurança no ambiente de trabalho e proteção social, além disto, permite o desenvolvimento pessoal e profissional, e liberdade para diálogo e reivindicações, participação nas decisões que afetam a vida laboral e possibilidade de organização da categoria.

O trabalho via plataformas digitais, não obstante tenha sido inicialmente visto como possibilidades de maiores ganhos financeiros e autonomia, é na prática, um sistema de superexploração do trabalho. Efetivado em sistema de ranking e pontuação, bloqueios indevidos e baixa taxa de entrega, que se traduzem em exigência de disponibilidade e dedicação integral ao trabalho, para que haja acesso a uma baixa remuneração. Para muitos dos trabalhadores, a única fonte de renda e sustento familiar. 
É imprescindível que haja regulação do Estado, visto que as condições de assalariamento e superexploração são notórias, para que os vínculos sejam identificados e os trabalhadores tenham acesso a direitos trabalhistas. Faz-se urgente ao acesso de uma legislação social protetora do trabalho para a categoria, inclusive o direito a negociações coletivas e sindicalização. Por isso tem sido de substancial importância a mobilização coletiva e organização da classe para reivindicação por condições dignas de trabalho para a categoria.

Uma das possibilidades, dentro das flexibilizações trazidas com a Reforma Trabalhista (2017), é a modalidade de contrato de trabalho intermitente para os entregadores, para o primeiro momento, enquanto não há uma regulamentação específica. Alternativa reiterada por Antunes e Braga (2020) quando apontam que essa adequação poderia servir como uma transição mais segura do que a realidade totalmente desprotegida, através da inserção dos trabalhadores ao sistema protetivo, sobretudo, à seguridade pública. De forma que o contrato via CLT possibilita a identificação da massa trabalhadora e a remuneração com base na lei do salário mínimo, assim como a regulação da jornada de trabalho com garantia do descanso remunerado.

No tocante à mobilização da categoria, criar caminhos alternativos de formas de autogestão e organização do trabalho é uma possibilidade que precisa ser aprofundada, como, por exemplo, o cooperativismo com aplicativo próprio de entrega e gestão democrática. Decerto, como principais barreiras ao uso de ferramentas tecnológicas próprias de trabalho, têm-se os custos iniciais de desenvolvimento de uma plataforma digital; a capacidade de articulação regional e nacional do aplicativo, no quesito operação em escala, bem como a regulamentação da criação de cooperativa.

Conforme Scholz (2016), os fatores que fundamentam a atual configuração das relações via plataformas digitais são a facilidade e a rapidez de atendimento do mercado tanto pelo lado da oferta quanto da demanda, através do uso da tecnologia, modificando substancialmente as formas de consumo, as relações de trabalho e as estruturas dos setores, sobretudo o de serviços. Ao que o autor definiu como ubercapitalismo, cuja dinâmica desequilibra os fundamentos da legislação trabalhista e das relações de trabalho. Neste sentido, a precarização das condições de trabalho 
e a desregulamentação, implicam na ausência de mecanismos mínimos de proteção social.

Isto porque, como apontam Antunes e Braga (2020), capitalismo financeiro digital, neoliberalismo e tecnologia de ponta acabam por formar, muitas vezes, uma tríade de mecanismos de precarização das relações laborais e destruição do tecido social, servindo para alavancar a crise social, as desigualdades de renda e a pobreza.

A OIT (2019) traça um panorama de princípios norteadores para garantia do trabalho decente nas plataformas digitais, quais sejam: estabelecer algum vínculo de trabalho; permitir o exercício da organização da categoria e da negociação coletiva; garantir que o trabalho exercido tenha um retorno de, ao menos, um salário mínimo vigente no país; garantir transparência no pagamento do trabalho e das comissões cobradas pelas plataformas; dar autonomia de escolha aos trabalhadores sobre executar ou não a atividade, de acordo com sua própria gestão do tempo de trabalho; cobertura dos custos do trabalho; e garantir que os trabalhadores tenham direito ao diálogo e à contestação.

A organização recomenda ainda que sejam feitas adaptações nos sistemas de proteção social do trabalho de maneira a englobar a modalidade em questão, garantindo a cobertura dos trabalhadores por mecanismos de seguridade social. Criando mecanismos de proteção social universais, financiados com impostos, que abranjam todas as modalidades de emprego, independentemente do tipo de contrato.

Em um contexto de reestruturação econômica, com forte presença de corporações globais é preciso fomentar outras formas de organização das relações sociais e laborais que se contraponham ao atual sistema de exploração do capital. Vislumbrando, assim, a construção de outras vertentes de inclusão social e alternativas de existência digna.

Concomitante ao processo de mobilização e organização dos trabalhadores, dialogar com outras experiências de organização da classe trabalhadora, visto que o contexto de grandes empresas globais perpassa diferentes setores, possibilita a troca de ideias e novas articulações. A integração entre diferentes iniciativas fomenta ainda a mobilização popular e a organização política para lutar por melhores condições de trabalho. Bem como por políticas públicas específicas, que são ferramentas possíveis de transformação das diferentes realidades e superação das desigualdades. Através delas, recursos são destinados para financiar direitos e bem-estar social. E se traduzem em autonomia, conquistas de renda e de direitos sociais e trabalhistas. 
O Estado, enquanto agente propulsor e regulador, deve promover a integração de um projeto nacional, regional e local de desenvolvimento econômico e social, que transversalizem as distintas características da população brasileira, considerando, assim, as especificidades dos diferentes grupos sociais com maior vulnerabilidade ao desemprego.

Só através de políticas de investimentos e de programas de estímulo à produção, diversificação produtiva e fortalecimento das cadeias produtivas, além dos investimentos sociais em educação e ações afirmativas para combater desigualdades de acesso, é que o Estado vai promover a dinamização da economia e a fomentar a geração de empregos. E não seguindo uma agenda de flexibilização desenfreada do mercado de trabalho que se traduzem em ocupações precárias e condições de vida bastante adversas para a classe trabalhadora.

\section{CONSIDERAÇÕES FINAIS}

A financeirização do capital, atrelada a componentes políticos-institucionais correlacionados à desregulação do mercado de trabalho e a estruturação de novas configurações e dimensões do mercado de bens e serviços, e do mercado financeiro, traduziu-se em avanços da precarização das condições de trabalho, expansão do desemprego, bem como da informalidade como alternativa de subsistência. Concomitante, o processo de reformas modernizadoras das relações laborais, como justificativa para aumento do nível de emprego no país, tem culminado em criação de postos de trabalho com menor proteção social e com baixas remunerações.

Neste sentido, a expansão da informalidade tem mascarado o maior impacto do desemprego, no país, ao dar como solução a inserção de trabalhadores sem carteira assinada ou por conta própria, que vivem às margens dos direitos sociais e trabalhistas previstos. O que configura uma realidade de forte deterioração das condições de trabalho no período recente.

No atual contexto de crise sanitária, os mais atingidos pela pandemia são os que já são mais afetados pela desigualdade no país. Desta forma, a tendência para o mundo do trabalho durante e depois da pandemia é o aprofundamento da precarização do trabalho, a partir, sobretudo, da desregulação e desproteção das relações laborais, bem como da mercantilização de direitos sociais. É diante deste 
cenário que avança o processo de digitalização precarizada e exploração da força de trabalho, através da uberização do trabalho.

Em relação às medidas de modernização das relações laborais, a Reforma Trabalhista não tem atendido as expectativas de criação de empregos formais e de crescimento econômico, diante de um cenário de baixo dinamismo da economia. Haja vista o crescimento do número de desocupados, subocupados e desalentados, somado ao alto número de trabalhadores informais, nos últimos anos. No que concerne às implicações durante a pandemia, os dados da Pnad Contínua demonstram que os impactos da pandemia têm atingido mais fortemente categorias ocupacionais que já se encontravam em condições de vulnerabilidade e desigualdade no país, sobretudo aqueles cujas atividades estão relacionadas a trabalhos informais.

O trabalho digital precarizado configura-se como forte representação das novas formas de organização do trabalho em uma economia digital, assim como da tendência máxima de desmantelamento da rede de proteção social do trabalho. São trabalhadores submetidos à exaustiva jornada de trabalho, remuneração baixa, ausência de direitos trabalhistas, e invisibilização social pelo Estado.

É fundamental que haja regulação do Estado, bem como promoção de políticas públicas de proteção social, de assistência financeira e de acesso dos trabalhadores autônomos e pequenos empreendedores a crédito e serviços financeiros e nãofinanceiros. A respeito da realidade dos trabalhadores por aplicativo, explanada neste estudo, é necessária também a organização da categoria em detrimento da ideia de empreendedor individualizado, bem como organização e mobilização para luta por direitos, e ainda, em forma de representação coletiva. Haja vista que esta articulação coletiva é imprescindível para toda e qualquer classe trabalhadora.

O Estado deve proteger a classe trabalhadora, sobretudo os estratos sociais mais vulneráveis, no lugar de permitir que o mercado funcione livremente, posto que o mesmo não se autorregula, e isso se traduz na exploração cada vez mais acentuada dos trabalhadores. Tem-se, assim, a extração da força de trabalho em moldes mercantis e servis.

\section{REFERÊNCIAS}

ABÍLIO, L.C.; ALMEIDA, P. F.; AMORIM, H.; CARDOSO, A.C.; FONSECA, V.; KALIL, R.; MACHADO, S. Condições de trabalho em empresas de plataforma 
digital: os entregadores por aplicativo durante a Covid-19. Relatório parcial da pesquisa. São Paulo: REMIR, 2020. 11 p.

ANTUNES, R. O privilégio da servidão: o novo proletariado de serviços na era digital. São Paulo: Boitempo, 2018.

ANTUNES, R; BRAGA, R. Greve dos entregadores expõe precarização do trabalho por aplicativos. [entrevista concedida a] Conectas. Portal Conectas Direitos Humanos: São Paulo, 1ํ de julho, 2020. Disponível em: https://www.conectas.org/noticias/greve-entregadores-precarizacao-trabalhoaplicativos. Acesso em: 02 de julho de 2020.

BARROS, V. A; OLIVEIRA, M. Q; NEVES, C. V; Dimensões psicopolíticas da prostituição: a relação prostituta e trabalho. In: Trabalho: diálogos multidisciplinares. Daisy Moreira Cunha, João Bosco Laudares, org. Belo Horizonte: editora UFMG, 2009'

BRAGA, R. A política do precariado: do populismo à hegemonia lulista. São Paulo: Boitempo, 2012.

BRASIL. Lei no 13.467, de 13 de julho de 2017. Brasília, DF: Presidência da República, 2020. Disponível em http://www.planalto.gov.br/ccivil_03/_ato20152018/2017/lei/l13467.htm Acesso em 26 de junho de 2020.

. Lei no 14.020, de 6 de julho de 2020. Brasília, DF: Presidência da República, 2020. Disponível em http://www.planalto.gov.br/ccivil_03/_Ato20192022/2020/Lei/L14020.htm. Acesso em 08 de julho de 2020.

CARVALHO, L. Valsa brasileira: do boom ao caos econômico. São Paulo: Boitempo, 2018.

CARVALHO, S. S. Os efeitos da pandemia sobre os rendimentos do trabalho e o impacto do auxílio emergencial: o que dizem os microdados da PNAD covid-19. Carta Conjuntura no 48. Brasília: IPEA, 2020.

COELHO, D. Trabalho on demand por meio de aplicativos: uma análise à luz da subordinação. Revista do Tribunal Regional do Trabalho da $12^{a}$ Região. V.22. n 31. P. 107-123. 2019.

FILGUEIRAS, V.; BISPO, B.; COUTINHO, P. A Reforma Trabalhista como reforço a tendências recentes no mercado de trabalho. p. 126 - 155. In: Dimensões críticas da Reforma Trabalhista no Brasil. Org: José Dari Krein, Denis Maracci Gimenez, Anselmo Luis dos Santos. Campinas, SP: Curt Nimuendajú, 2018.

IBGE. Pesquisa Nacional por Amostra de Domicílios Contínua: primeiro trimestre de 2020. Rio de Janeiro: IBGE, 2020.

KALIL, R. B. Capitalismo de plataforma e direito do trabalho: crowdwork e trabalho sob demanda por meio de aplicativos. Tese de doutorado. USP: 2019. 
KREIN, J. D.; OLIVEIRA, R. V. Para além do discurso: impactos efetivos da Reforma nas formas de contratação. In: Reforma Trabalhista no Brasil: promessas e realidade. Org. José Dari Krein, Roberto Véras de Oliveira, Vitor Araújo Filgueiras. Campinas, SP: Nimuendajú, 2019.

MIRANDA, G. K. Mercado de trabalho: reforma trabalhista sob a perspectiva de gênero. TCC. UFRPE: 2019.

NOGUEIRA, M. O; A problemática do dimensionamento da informalidade na economia brasileira. Rio de Janeiro: IPEA, 2016.

OIT. Perspectivas sociales y de empleo en el mundo: avance global sobre las tendencias del empleo femenino. Genebra: OIT, 2018.

. Las plataformas digitales y el futuro del trabajo: como fomentar el trabajo decente en el mundo digital. Genebra, OIT, 2019.

ONU. Policy Brief: the impact of Covid-19 on Latina America and the Caribbean. 2020 Disponível em https://www.un.org/sites/un2.un.org/files/sg_policy_brief_covid_lac.pdf. Acesso em 10 de julho de 2020.

PEDUZZI, M. C. I. O Direito do Trabalho na era tecnológica: descentralização produtiva e novas formas de trabalho. In: X Congresso Internacional da ABDT: Crise econômica e social e o futuro do Direito do Trabalho. Anais do Congresso [livro eletrônico] / coordenação Alexandre Agra Belmonte, Luciano Carreiro, Yone Frediani. São Paulo: Matrioska Editora, 2020.

PEREIRA, S. O; CABRAL, J. P. Informalidade e crise do emprego no Brasil. In: Revista Humanidades e Inovação, v.6, n.18. p. 92-102. 2019. Disponível em https://revista.unitins.br/index.php/humanidadeseinovacao/article/view/1753 Acesso em 12 de agosto de 2020.

PUTTI, A. Proletariado digital. Carta capital. 8 de maio de 2019. Disponível em https://www.editoraconfianca.com.br/acesso/leitor Acesso em 12 de agosto de 2020.

SCHOLZ, T. Cooperativismo de plataforma: contestando a economia do compartilhamento corporativa. São Paulo: Fundação Rosa Luxemburgo; Editora Elefante; Autonomia Literária, 2016.

Recebido em: maio de 2020

Aceito em: julho de 2020 